\title{
ALGUMAS REFLEXÕES SOBRE O MAPEAMENTO GEOTÉCNICO
}

\author{
Lázaro Valentim Zuquette \\ Faculdade de Filosofia, Ciências e Letras de Ribeirão Preto/USP
}

\author{
Nilson Gandolfi \\ Escola de Engenharia de São Carlos/USP
}

A de uma região ocorre de maneiras diversas, sempre baseada em decisões políticas e nas possiveis atividades a serem desenvolvidas, quase sempre relegando as informações sobre o meio ambiente. A ocupação adequada de uma região deve buscar um equilibrio antrópica entre as ações antrópicas e o meio ambiente (meio fisico, meio biológico, ações antrópicas, condições sócio-econômicas e suas inter-relações). Dentre os componentes do meio ambiente, o meio fisico é a base para a implementação de qualquer tipo de ocupação.

Assim, para o planejamento adequado de uma área é necessário ter conhecimento básico entre o seu meio fisico (rochas, materiais inconsolidados, águas, relevo, condições climáticas e suas inter-relações). O conhecimento do meio físico é obtido através de um processo de mapeamento que o análise como um conjunto e avalie o comportamento dos seus componentes em termos de geotécnia e suas características de interesse à implementação das formas de ocupação. Os documentos produzidos por este processo compõem o mapeamento geotécnico e tem sempre o objetivo de orientar e não substituir as investigações geotécnicas locais.

A elaboração do mapeamento geotécnico deve se basear numa metodologia que oriente os trabalhos envolvidos nas diferentes etapas, assim como analisar quais os atributos do meio fisico e os níveis em que devem ser considerados para cada escala. O conhecimento do meio fisico tem importância fundamental, seja na orientação da ocupação, na elaboração de Eias/Rimas e mesmo na recuperação de áreas degradadas.

No Brasil, diversos trabalhos já foram elaborados em diferentes regiões por equipes ligadas às universidades, às empresas, aos institutos isolados de pesquisa e aos órgãos de prestação de serviços.

A nosso ver, um mapeamento geotécnico, para ser eficiente, deve estar apoiado em uma metodologia que atenda os seguintes pressupostos básicos:

- os atributos a serem considerados e o nivel de heterogeneidade aceitável e a classificação desses, variam em função da escala;

- a necessidade de ordenar a obtenção dos atributos quantitativos e qualitativos;

- deve-se homogeneizar as informações para que não ocorram excessos ou deficiências localizadas;

- definir como, quanto e onde realizar as amostragens;

-deve existir um documento básico (mapa topográfico adequado) para que mapeamentos específicos sejam elaborados em sequência, assim como estudos científicos sejam executados em locais determinados em termos de geologia de engenharia, pedologia, hidrologia, geomorfologia, biologia, geografia, etc.;

- definir as atividades que deverão ser desenvolvidas em cada uma das três fases do mapeamento geotécnico (preliminar, de escritório e campo; fase de campo e fase conclusiva); - estabelecer o nivel de generalização das informações que serão mais adequado; -realizar o mapeamento a um custo final que possa ser considerado baixo. 
Da análise do grande número de documentos, dentre os mais de mil existentes na bibliografia internacional, sobre o desenvolvimento e elaboração dos mapeamentos geotécnicos, nos mais diversos paises, pode-se concluir que atendem a três enfoques básicos: - como projeto de pesquisa, estudando metodologias, ensaios, análises dos terrenos, gênese e propriedades, com o objetivo de encontrar o melhor caminho para a realização do mapeamento geotécnico;

- como um projeto específico, a fim de dotar uma região de documentos básicos sobre o meio fisico, colocado à disposição dos diferentes usuários;

- como uma associação dos dois enfoques anteriores, principalmente em países na fase inicial de seus processos de desenvolvimento ou quando o mapeamento geotécnico é produzido por instituições que se dedicam à pesquisa e prestação de serviços.

$\mathrm{Da}$ abrangência dos principais conceitos sobre mapeamento geotécnico/cartografia, geotécnica/mapeamento, geológico-geotécnico, segundo: I.A.E.G., Varnes, Matula, Zuquette e Gandolfi, etc., conclui-se que ele é constituido de um conjunto de estudos que deve retratar o meio fisico de um ponto de vista pragmático de forma que permita, a diferentes categorias de usuários, obter não são informações básicas para orientação da escolha das áreas mais adequadas aos seus empreendimentos como também os critérios a serem utilizados nas investigações de detalhe que se fizerem necessárias.

Algumas questões ficam em aberto e denfre outras temos: a) quais atributos do meio fisico devem ser considerados? b) quais os procedimentos a serem seguidos? c) quais escalas devem ser adotadas?

Evidentemente, a experiência tem nos mostrado que cada região reúne características próprias, vindo a exigir procedimentos especificos de mapeamento geotécnico. Porém, não se pode esquecer que as diferentes formas de ocupação exigem do meio físico características básicas adequadas, e estas não ocorrendo acabam por suscitar a intervenção de procedimentos tecnológicos corretivos.

Conclui-se, portanto, que o meio fisico deve ser investigado na sua totalidade para permitir o atendimento das exigências relativas às diferentes formas de ocupação. Quando da realização de tal investigação, trás condições básicas de ocupação devem ser consideradas, a saber: 1) ocupação por uma obra específica, geralmente em pequena área do terreno; 2) por obras que atingem grandes áreas e finalmente, 3) por um arranjo das diferentes formas de ocupação numa região (área urbana e sua expansão, locais para aterros sanitários, acesso etc.), geralmente de grande extensão. Frequentemente, há uma certa indecisão quanto aos documentos cartográficos necessários para o atendimento das exigências consideradas. Para a primeira condição, há necessidade de um conjunto muito grande de informações, normalmente registradas numa planta geotécnica, onde são definidas as características finais de projeto e implementação. A segunda condição é típica de ocupações longitudinais, como estradas e dutos, que exigem uma otimização do arranjo regional e um detalhamento ao longo da faixa de ocupação. Para a última condição, onde sempre se considera grandes áreas, são exigidos documentos sobre o meio fisico em escalas que permitam uma visão regional.

Quando não se leva em conta tais condições em que as ocupações se desenvolvem, frequentemente é exigido um detalhamento muito grande das informações, praticamente a nivel de planta geotécnica, qualquer que seja a escala do mapeamento geotécnico, resultando críticas improcedentes dos usuários mal informados ou pouco familiarizados com tais documentos.

Isso leva à necessidade de se considerar alguns aspectos sócio-técnico-econômicos vigentes no País, a saber:

10 A maioria das formas de ocupação do meio físico não apresenta estudos prévios, onde se 
deveria definir o custo/beneficio para a implementação e as limitações inerentes ao meio; frequentemente o contratante não apresenta capacidade para escolha da proposta mais adequada;

$2^{\circ}$ Normalmente, os profissionais envolvidos com a implementação das diferentes formas de ocupação não são fiscalizados pelas associações profissionais ou pelos órgãos contratantes; $3^{\circ} \mathrm{Os}$ órgãos públicos responsáveis pelo planejamento regional não apresentam qualquer preocupação em compatibilizar e equilibrar as diferentes formas de ocupação em função das características do meio fisico das diferentes regiões;

$4^{\circ} \mathrm{Há}$ profissionais que, não atendendo às exigências do meio fisico, acabam por implementar formas de ocupação em locais com condições desfavoráveis, disso resultando a possibilidade de mais "trabalhos futuros";

$5^{\circ}$ Frequentemente obras públicas são destinadas a empresas "certas", sem que realmente haja uma decisão de natureza técnica;

$6^{\circ}$ As ocupações consideradas mais comuns, como loteamentos, saneamento e etc., não são questionadas ou avaliadas corretamente pelos órgãos públicos responsáveis;

$7^{\circ} \mathrm{Em}$ alguns ramos da ocupação, os projetos de obras são desenvolvidos com base em conhecimento obtido da prática (pessoal ou da empresa), sem que seja feita qualquer investigação do meio fisico, levando assim é reserva de domínio da área ocupada e dificuldade de fiscalização;

$8^{\circ}$ É comum a utilização de informações técnicas obtidas empiricamente, sem realização de análise abrangente dos diversos componentes do meio fisico.

Estes aspectos fazem com que um grupo de profissionais considere o processo de mapeamento geotécnico um trabalho sem utilidade ou que não traz o detalhamento necessário (desejado pelo profissional, para que não necessite da investigação local e assim "facilite" o seu trabalho). Esta consideração, quando analisada por profissionais que trabalham com o mapeamento geotécnico, leva à constatação que nunca é analisada pelos que criticam: Por que a maioria das ocupações implementadas não está em equilibrio, harmonizada com outras? Por que há problemas de movimentos de massas, erosão, obras inacabadas, inundações, recalques, poluição? Qual a razão do custo de obras muito acima da realidade de outros paises?

$\mathrm{E}$ assim, na maioria das vezes, surge o interesse por realizar o mapeamento geotécnico para tentar solucionar o problema que está ocorrendo ou para tentar evitar a sua continuidade, que se caracteriza como Mapeamento com finalidade "curativa".

Analisando estas poucas situações, é possivel formular uma série de novos questionamentos, quando se pensa em planejamento e na relação custo/benefício/meio ambiente:

- Por que não elaborar Mapeamento Geotécnico para fins preventivos, sejam gerais ou especí ficos?

- Os técnicos de maneira geral, estão realmente capacitados a desenvolver projetos de ocupação de maneira que atendam às condiões mínimas de equilibrios custo/beneficio e regional?

- Quanto dinheiro foi gasto além do necessário para realização de muitas obras? - Quanto vai ser necessário para recuperar as áreas degradadas?

- Como realizar planos diretores sem o conhecimento adequado do meio fisico que é a base para todas as formas de ocupação? Os realizados até o momento sãoo reais?

- Como produzir estudos sobre o meio ambiente (meio fisico, meio biológico, ações antrópicas e suas relações), sem conhecer o meio fisico? 
- Como escolher áreas, por exemplo, para aterros sanitários sem considerar o meio físico de maneira regional?

- Quantos estudos sobre as características do meio físico, das águas, etc. são realizados, por exemplo, nos projetos de irrigação?

- Qual a porcentagem da extensão do País que tem o seu meio fisico conhecido numa escala compativel, como por exemplo 1:50.000?

Com este grupo de questões, é possivel concluir que a resistência a realização e utilização do mapeamento geotécnico deve ser creditada em grande parte a técnicos que: não têm conhecimento sobre as condições necessárias para que as formas de ocupação sejam implementadas adequadamente, ou têm interesse em ganho, sem se preocupar com os problemas futuros ou ainda preferem ter "seus zoneamentos geotécnicos" baseados na prática, dificultando a atuação de outros técnicos.

$\mathrm{Da}$ interação entre as características dos técnicos envolvidos com o meio físico, as necessidades de informações para que realmente a ocupação seja desenvolvida adequadamente e as características sócio-econômicas vigentes, é notória a importância de se ter os conhecimentos globais do meio físico, constantes do mapeamento geotécnico, conforme se observa na maioria absoluta dos trabalhos produzidos nos paises mais desenvolvidos.

A elaboração dos mapeamentos geotécnicos se depara com problemas inerentes às características do meio físico, do meio técnico, das condições sócio-econômicas e dos técnicos envolvidos. Porém, no Brasil, uma das críticas mais comuns com que se defronta, refere-se à precisão e detalhamento das informações contidas nos documentos gráficos.

Segundo esse ponto de vista, pode-se afirmar que há um confronto entre os profissionais que investigam a nivel local e aqueles que trabalham com espaços tridimensionais extensos. Para a análise deste confronto, é necessário considerar as seguintes questões:

- qual o significado e as condições de extrapolação das informações pontuais?

- quais os crité rios que condicionam os estudos localizados e os especificos?

- finalmente, como relacionar características genéticas dos materiais, normalmente obtidas espacialmente, com as informações locais, em geral obtidas pontualmente e de maneira empirica?

A atuação do grupo de trabalho de São Carlos relaciona-se tanto à formação de recursos humanos para o desenvolvimento do mapeamento geotécnico, principalmente de natureza preventiva, quanto à pesquisa de natureza metodológica referente aos procedimentos para elaboração de tal mapeamento.

Para a consecução desses objetivos, foi selecionada uma extensa e importante área localizada na região centro-leste do Estado de São Paulo, por apresentar alguns fatores bastante significativos, dos quais podemos destacar:

- grande diversidade de relevo e de litologia;

- necessidade de definição de áreas para implantação de obras públicas;

- grande crescimento populacional e industrial;

- grande número de núcleos urbanos em processo de expansão. Tal área corresponde a 24 folhas na escala 1:50.000, do IBGE, das quais 14 já foram mapeadas e as restantes encontram-se em fase de execução. 